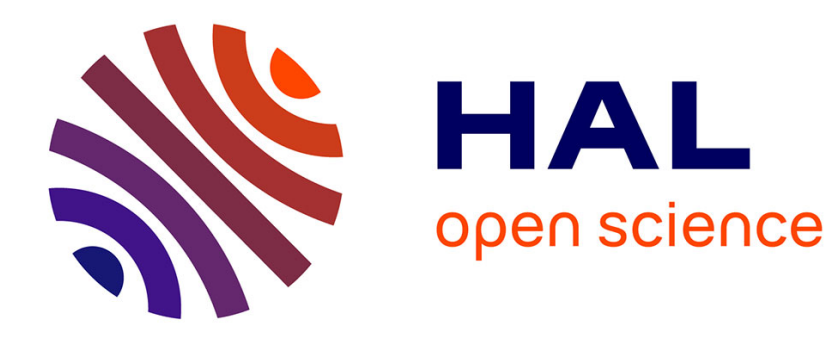

\title{
Caesium flooding on metal surfaces and sputtered negative ion yields
}

\author{
M. Bernheim, G. Slodzian
}

\section{To cite this version:}

M. Bernheim, G. Slodzian. Caesium flooding on metal surfaces and sputtered negative ion yields. Journal de Physique Lettres, 1977, 38 (15), pp.325-328. 10.1051/jphyslet:019770038015032500 . jpa00231387

\section{HAL Id: jpa-00231387 https://hal.science/jpa-00231387}

Submitted on 1 Jan 1977

HAL is a multi-disciplinary open access archive for the deposit and dissemination of scientific research documents, whether they are published or not. The documents may come from teaching and research institutions in France or abroad, or from public or private research centers.
L'archive ouverte pluridisciplinaire HAL, est destinée au dépôt et à la diffusion de documents scientifiques de niveau recherche, publiés ou non, émanant des établissements d'enseignement et de recherche français ou étrangers, des laboratoires publics ou privés. 


\title{
CAESIUM FLOODING ON METAL SURFACES AND SPUTTERED NEGATIVE ION YIELDS
}

\author{
M. BERNHEIM and G. SLODZIAN \\ Laboratoire de Physique des Solides $\left({ }^{*}\right)$, Université Paris-Sud, 91405 Orsay, France
}

(Reçu le 13 juin 1977, accepté le 1er juillet 1977)

\begin{abstract}
Résumé. - La distribution en énergie et les rendements en ions secondaires négatifs ont été mesurés sur des cibles métalliques recevant simultanément un flux de césium et un bombardement d'ions argon. Des taux d'ionisation proche de l'unité ont été obtenus sur les métaux nobles.

Abstract. - Energy distributions and yields of secondary negative ions were measured when metallic surfaces were simultaneously flooded with caesium and bombarded with argon ions. Negative ionization yields near one were obtained on noble metals.
\end{abstract}

1. Introduction. - The influence of chemical bonding on secondary ion emission yields has been a strong incentive to look for ways of modifying the chemical composition of surface layers. The change of composition can be achieved either by blowing a reactive gas onto the sample being bombarded, or by implanting reactive atoms by means of the bombarding ion beam. The latter way has been shown to have the inconvenience of often leading to superficial layers which are not saturated by reactive atoms [1]. Moreover, on a polycrystalline target, the reactive atom concentration at the surface may vary from one grain to another.

In recent years, several authors have shown that the yield of negative ions may be strongly increased by using caesium primary ions $[2,3,4]$. Although the chemistry involved here is quite different from that usually implied with other reactive primary ions $\left(\mathrm{O}_{2}^{+}\right.$, halogens, ...), the foregoing consideration must be still valid. This paper reports some results on the enhancement of negative ion yields obtained by flooding the sample surface with caesium vapour while bombarding the sample with argon ions.

2. Experimental conditions. - A mass-analysed primary argon beam was directed against the sample surface. The secondary ion collecting optics was that of the direct imaging instrument [5]. The sample could be rotated about the axis of the collecting optics, the collection efficiency remaining the same at any azimuthal position. The purpose of rotating a monocrystalline sample was to modify the sputtering yield

(*) Laboratoire associé au C.N.R.S. which is known to depend on the crystal transparency seen by the primary ions. A combination of a magnetic and an electrostatic prism allowed the secondary ions to be analysed both in mass and energy [6]. For the sake of simplicity, three filaments [7] provided the caesium feeding. During the experiments the pressure in the vacuum chamber was about $5 \times 10^{-8}$ torr.

3. Experimental results. - 3.1 LATTICE EFFECTS ON NEGATIVE ION YIELDS. - First, a caesium free (100) face of a copper single crystal was bombarded with a beam of $\mathrm{Ar}^{+}$ions of $9.6 \mathrm{keV}$ whose angle of incidence on the sample was $46^{\circ}$. The $\mathrm{Cu}^{+}$currents were recorded versus the azimuthal angle $\psi$ and served as a reference for the variations of sputtering yields with azimuthal position.

Then the same samples was simultaneously fed with caesium vapour and bombarded by a beam of $\mathrm{Ar}^{+}$ions (10.5 keV energy, $44^{\circ}$ incidence angle). The currents were plotted against the azimuthal angle $\psi$.

Figures $1 a, 1 b, 1 c$ correspond to increasing caesium fluxes : curve ( $1 a)$ was recorded with a weak caesium flow and it can be observed that highly transparent directions lead to low sputtering yields and exhibit high $\mathrm{Cu}^{-}$currents. From figures $1 b$ and $1 c$, one can see that saturation is not obtained for the same flux at opaque and transparent positions.

From these results one may infer that the caesium coverage controls the ionization yield of negative ions. At low fluxes, a lower sputtering yield results in a higher caesium coverage and thus in a higher ionization yield. However, when the caesium coverage increases, the change in surface composition tends to lower the sputtering yield of copper atoms; but 


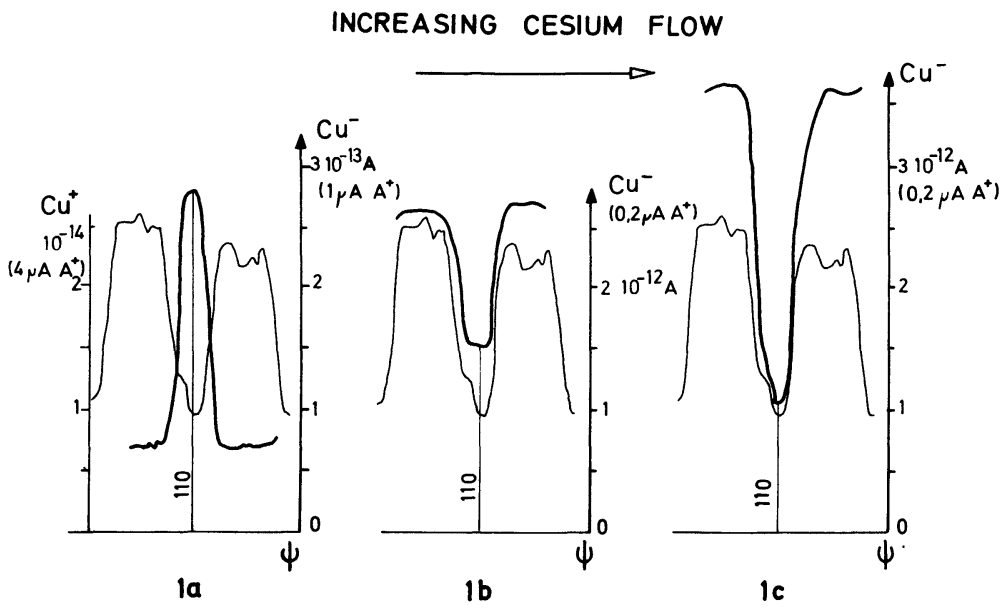

FIG. 1. - Azimuthal recordings of $\mathrm{Cu}^{+}$(thin line, scales on the left) and $\mathrm{Cu}^{-}$(thick line, scales on the right) for low initial energies. The $\mathrm{Cu}^{-}$curves were plotted after a caesium coverage equilibrium was reached at each azimuthal position. The density of the primary argon beam is indicated on the figure in each case.

simultaneously, a considerable enhancement of ionization yield occurs which exceeds the lowering of the sputtering yield. Then a point is reached where the decrease of the copper sputtering yield can no longer be compensated for by a further increase of ionization yield. An extreme case could be reached where caesium would arrive at the surface at a rate which could not be balanced by sputtering; a caesium film would then build up preventing copper from being sputtered.

3.2 IONIZATION YIELDS. - Let $n_{i}$ be the number of $\mathbf{M}^{-}$ions which reach the detector as the sample volume $v_{0}$, containing $n_{0}$ atoms $\mathrm{M}$, is sputtered. We define the practical ionization yield as the ratio $\tau=n_{i} / n_{0}$. In order to measure $\tau$, we first have to determine $v_{0}$. Since the field being analysed is known (150 microns in diameter) it is only necessary to measure the depth of a crater or to sputter a thin evaporated film of known thickness.

We made measurements on copper and gold films with a caesium flow adjusted so as to obtain maximum $\mathrm{M}^{-}$currents. In order to provide a better collection efficiency, the bombarding and collecting conditions were somewhat different from those of the foregoing paragraph (the sample voltage was set at a higher value changing the energy of the primary ions $(14 \mathrm{keV})$ and the incidence angle of the primary beam was $\left.34^{\circ}\right)$. On copper films (1 $200 \AA$ ) flooded with caesium we obtained a practical yield of about $2.5 \times 10^{-2}$ once the correction to $100 \%$ isotopic abundance had been made; the spectrometer had a $0.4 \mathrm{eV}$ energy interval. The copper sputtering yield was measured to be 2 atoms per primary ion; the sputtering rate was $0.36 \mathrm{~A} / \mathrm{s}$. In the same conditions, the practical yield measured on gold was found to be $8.5 \times 10^{-2}$. It should be noted that from the energy distribution curves (given elsewhere in this paper) it can be computed that for the energy interval $0-10 \mathrm{eV}$, the practical yield of $\mathrm{Cu}^{-}$ions would be equal to $5.6 \times 10^{-2}$ and would reach $7.5 \times 10^{-2}$ for the energy interval 0-150 eV.

Assuming now that the distribution in angle of $\mathrm{M}^{-}$ ions follows a Lambert's law, one may reckon that the total yield is about $40 \%$ for copper and nearly $100 \%$ for gold for the energy interval $0-150 \mathrm{eV}$.

3.3 ElEmental anAlysis on ALlOys. - We examined copper-nickel alloys of known composition just to make sure that the ratio of the ionization yields of $\mathrm{Ni}^{-}$and $\mathrm{Cu}^{-}$had a constant value. This ratio appeared to be constant and reproducible only above a given caesium coverage. In addition, we could check that oxygen partial pressure had no influence on ionization yield once the caesium saturation condition were reached.

Table I shows the ratios of ionization probabilities of the nickel and copper measured for various alloy concentrations (the ratio has been corrected to $100 \%$ isotopic abundance). These ratios are not as constant as one could wish. We latter found out that the higher concentrated alloys had oxide dots. Thus a question remains as to the possibility of performing quantitative analysis on samples containing small precipitates.

TABLE I

Atomic concentrations

$$
\frac{R\left(\mathrm{Ni}^{-}\right)}{R\left(\mathrm{Cu}^{-}\right)}
$$

$$
1.1 \% \quad 3.2 \%
$$

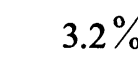$$
\text { - }
$$$$
0.32 \pm 0.03
$$

$0.34 \pm 0.03$

$$
(10.7 \%)
$$


4. Energy distribution. - In figure 2 we present two energy distributions performed on a gold sample (the dotted curve refers to a sample receiving caesium in excess). One can see that the two energy distributions are the same. It should also be noted that above $20 \mathrm{eV}$ the intensity of $\mathrm{Au}^{-}$falls as the inverse of the square of the initial energy $\Phi$ (whereas $\mathrm{Cs}^{+}$ions emitted from a gold sample at low caesium coverage vary like $\Phi^{-3}$ in the same energy range).

Figure 3 shows the energy spectra on copper and silver samples. It is interesting to note that $\mathrm{Cu}^{-}$ and $\mathrm{Ag}^{-}$follow nearly the same law as $\mathrm{Au}^{-}$.

If we account for the fact that collection solid angles around the normal direction are proportional to $\Phi[5]$ we arrive at the conclusion that gold particles sputtered from a caesium-covered sample the normal direction have an energy spectrum which decreases as $\Phi^{-1}$, whereas the energy spectrum of $\mathrm{Cs}^{+}$particles sputtered from a gold surface (almost free of caesium) decreases as $\Phi^{-2}$.

5. General discussion. - Our measurements suggest that $\mathrm{Au}^{-}$ions are emitted with nearly one hundred percent efficiency. Assuming that ionization processes depend on resonance charge exchange between the

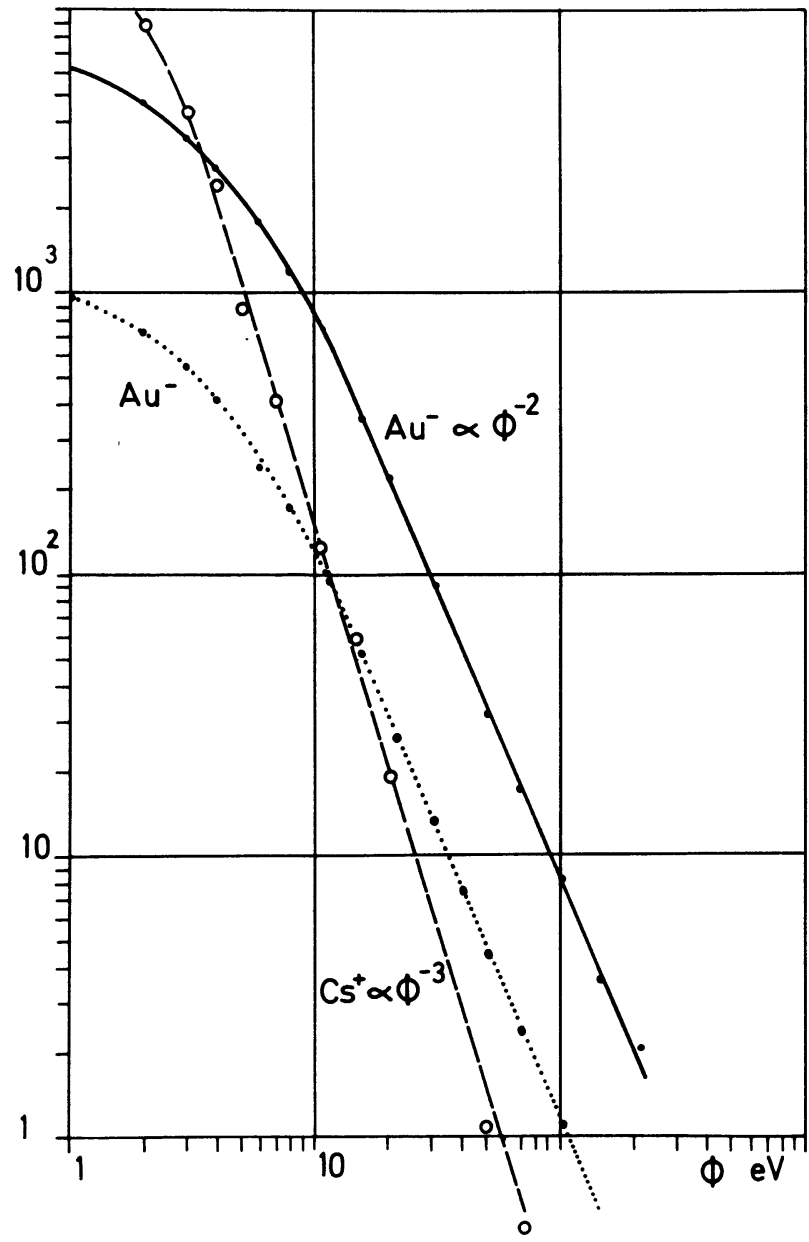

FIG. 2. - Energy distribution of $\mathrm{Au}^{-}$measured on gold at two different coverages (the dotted curve corresponds to an excess of caesium).

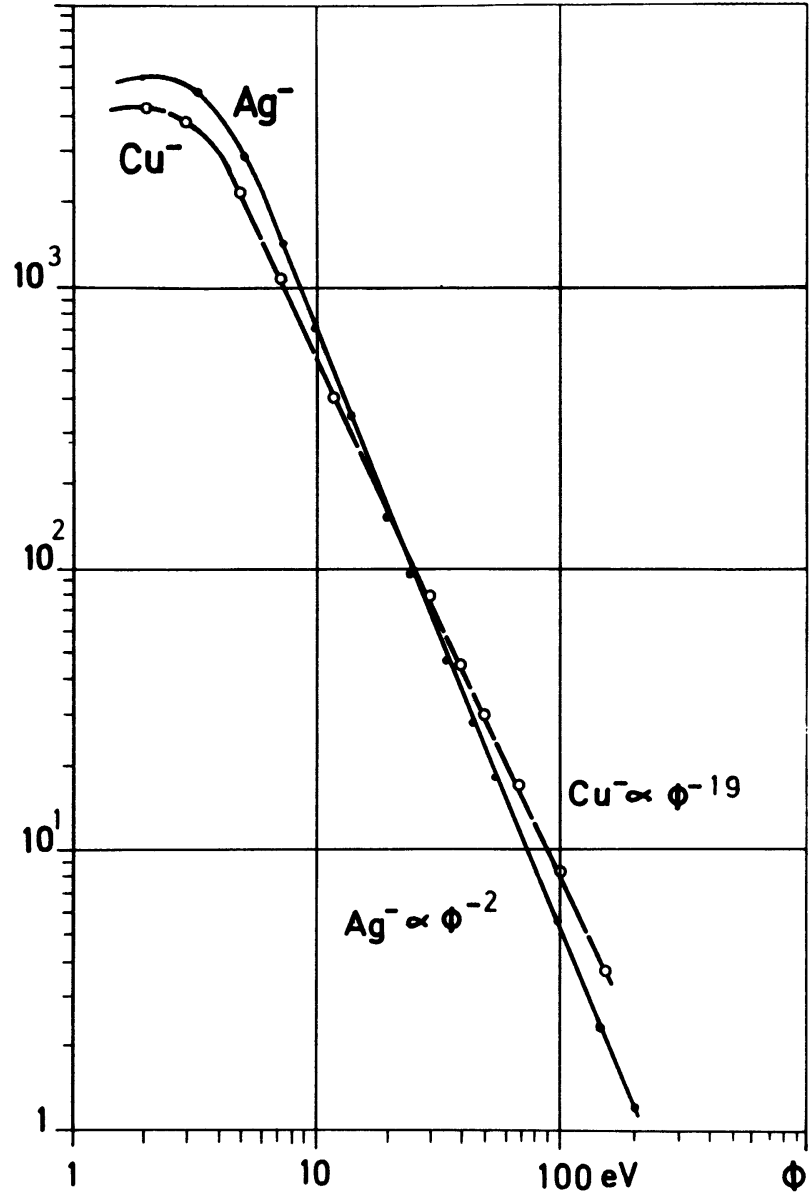

FIG. 3. $-\mathrm{Cu}^{-}$and $\mathrm{Ag}^{-}$energy distributions measured on copper and silver covered with caesium. (The primary argon ions (energy $14 \mathrm{keV}$ ) strike the sample at $34^{\circ}$ incidence angle.)

particle leaving and the sample surface it is not surprising to find such a high yield since the work function of the surface covered with caesium is likely to be lower than the electron affinity $2.3 \mathrm{eV}$ of gold atoms [8].

The situation is symmetrical for $\mathrm{Cs}^{+}$emission from a gold surface almost free of caesium since the work function of gold is higher here than the ionization energy of caesium. However, the energy spectra of $\mathrm{Cs}^{+}$ and $\mathrm{Au}^{-}$are quite different.

The $\mathrm{Cs}^{+}$energy spectrum falls off, as one would expect from the literature [9], for neutral atoms. But surprisingly, the $\mathrm{Au}^{-}$energy spectrum follows a law ascribed to focused collision sequences. This might be related to the fact that gold atoms are emitted from superficial films containing caesium at high concentration which could change the binding energy of surface atoms.

If the work function of caesium $(1.8 \mathrm{eV})$ set a lower limit for the work function value that can be obtained on the composite target surfaces, the negative ionization probability of metallic elements (except gold and platinum) should be lower than one since most elements have electron affinities lower than $1.8 \mathrm{eV}$. 
However, at room temperature, the processes at work in the promotion of one electron from the top of the Fermi sea to the level set by the electron affinity are not completely understood. More results on alloys are needed.

An important point to be emphasized is that caesium flooding produces higher ionization yields, as can be deduced by comparing our results with results already published [3]. For instance, in the relative intensity diagram given by $\mathbf{H}$. A. Storm et al., the primary yield of $\mathrm{Cu}^{-}$(number of $\mathrm{Cu}^{-}$ions produced per primary particle) is given to be $1.5 \times 10^{4} \mathrm{cps} / \mathrm{nA} \mathrm{Cs}{ }^{+}$, that is $2.5 \times 10^{-5} \mathrm{Cu}^{-}$per $\mathrm{Cs}^{+}$primary ion. Taking our results for the energy interval $0-10 \mathrm{eV}$ we can compute a primary yield equal to $0.1 \mathrm{Cu}^{-}$per $\mathrm{Ar}^{+}$primary ion. Thus, in this case, caesium flooding appears to be $4 \times 10^{3}$ times more efficient than caesium bombardment. If similar calculations are done for gold, the foregoing ratio drops to $5 \times 10^{2}$. But it should be noted that our comparison could be wrong if the collection efficiency were much lower in the cited experiments than in ours or if our sputtering yields were higher. Nevertheless, the other results included in the cited diagram indirectly confirm our statement in favor of caesium flooding. For instance, $\mathrm{S}^{-}$has a primary yield 25 times higher than that of $\mathrm{Au}^{-}$. This result is consistent with the assumption that caesium bombardment cannot build up a superficial film containing caesium at a concentration high enough to allow the maximum of the negative ion yield to be reached. Indeed, if the maximum of $\mathrm{Au}^{-}$yield is $100 \%$, it is impossible to get a higher yield for $\mathrm{S}^{-}$since it is doubtful that a difference in sputtering yield could account for a factor of 25 . Let us observe that the high sputtering yield of gold accounts well for a low caesium concentration.

Acknowledgments : The author wishes to thank $\mathrm{Ph}$. Le Maître for his technical assistance.

\section{References}

[1] Bernheim, M. and Slodzian, G., Int. J. Mass. Spectr. Ion Phys. 20 (1976) 295.

[2] Krohn, V. E., J. Appl. Phys. 33 (1962) 3523.

[3] Storms, H. A., Stein, J. D. and Brown, F. K., A. R. L. Probe news (April 1976) Joint US/Japan Seminal on SIMS technique, Honolulu.

[4] Williams, P., Lewis, R. K. and Evans, C. A., Anal. Chem. to be published.
[5] SLOd/IA \. G.. Surf. Sci. 48(1975) 161.

[6] Bernheim. M.. Thèse Orsay (1973).

[7] Alkali metal dispensers provided by SAES (Milano).

[8] Hotop, H., Lineberger, W. C., J. Phys. Chem. Ref. Data 4 (1975) 539.

[9] Chapman, G. E., Farmery, B. W., Thompson, M. W. and WILSON, I. H., Rad. Eff. 13 (1972) 121. 